\title{
A FLUORESCENCE-BASED ASSAY FOR OCTREOTIDE IN KINETIC RELEASE FROM DEPOT FORMULATIONS
}

Luiz Henrique Guerreiro, Wendell Girad-Dias, Kildare R. de Miranda e Luís Mauricio T. R. Lima*

Centro de Ciências da Saúde, Universidade Federal do Rio de Janeiro, Av. Carlos Chagas Filho, 373, Ilha do Fundão, 21941-902

Rio de Janeiro - RJ, Brasil

Recebido em 2/8/11; aceito em 25/11/11; publicado na web em 28/2/12

\begin{abstract}
Here we report the validation of a derivatization method that makes use of fluorescamine as a selective reactant for the quantitative analysis of peptide and protein drugs in the dissolution profile from depot formulations. Typical current methods require separation of the nano/microparticles and time-consuming chromatographic runs. In this study we report a method which can be conducted without the need for complete physical separation of the particles or removal of the unreacted probe. This method was used here for the analysis of the release profile of octreotide in a depot formulation, with results in excellent agreement with reported chromatographic assays.
\end{abstract}

Keywords: octreotide; fluorescamine; controlled release.

\section{INTRODUCTION}

Long-acting release formulations, based on nano and microparticle obtained with polymers such as PLGA and PCL represent a great advance in the therapeutic administration of novel and patentexpired drugs and biopharmaceuticals. ${ }^{1,2}$ The use of these products allows formulations to be administrated in schemes such as once in a month yielding controlled and sustained release of the drugs for a long period of time. In order to achieve the desired release profile, several formulations need to be tested, since most formulation parameters and chemistry affects the final product, its particle distribution and morphology, and thus influencing the release profile. ${ }^{3}$ In this development process, quantitative analysis of the release profile can be a rate-limiting step, and a high throughput analytical technique allowing the fast, low cost and accurate analytical method is convenient indeed.

Octreotide is a somatostatin analog used in the treatment of acromegaly (EP0029579; US4650787). ${ }^{4}$ To date, there is no official monograph for octreotide acetate in the main (US, European, British, and Brazilian) pharmacopeias. A depot formulation for intramuscular injection, based on polymeric microparticles comprising branched star-glucose PLGA ${ }^{5-7}$ (US5922682) became available in the 1990', which allowed the continued release of the octreotide for up to one month (US5538739). ${ }^{7}$ With the proximity of patent expiration (2011 for some countries), pharmaceutical laboratories are becoming motivated in the development of a generic or similar formulation (US2010086597). ${ }^{6,8-12}$ The analysis of octreotide can be performed by phase-reversed chromatography (US Pharmaceutical Forum 36, 6) ${ }^{7,8,13}$ However, RP-HPLC is highly time-consuming and costly, requiring the careful removal of the remaining particles, being a limiting step in the analysis of multiple samples from testing formulations.

In order to address this issue, we have focused in the development of a simple, rapid and effective method for the quantitative analysis of octreotide acetate released from polymeric microparticles in kinetic assays. Our method is based on a fast derivatization of primary amino groups of aminoacids (such as N-terminal and lysine) with fluorescamine, ${ }^{14,15}$ followed by the measurement of the resulting fluorescence from the reaction product. Our approach follows the orientation provided by both the International Conference of Harmonization (ICH) ${ }^{16}$

*e-mail: lml@ufrj.br and the Brazil's National Health Surveillance Agency (ANVISA) Guidelines. ${ }^{17}$ This approach is appropriated for the fast analysis of multiple samples, which may be performed in fluorescence readers using multiwell microplates. We discuss the extension of the present method to the use in the kinetic release study of other peptide and protein therapeutics.

\section{EXPERIMENTAL}

\section{Reagents}

Fluorescamine (CAS No. 38183-12-9) was purchased from Sigma-Aldrich Brazil. Octreotide acetate, in the active pharmaceutical ingredient form (API; CAS 83150-76-9, Product Cat \#

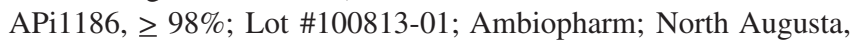
SC, USA; HB, 99.6\%; Lot \#20101201; HyBio Pharmaceutical Co., Keji, China) and Sandostatin ${ }^{\circledR}$ LAR $^{\circledR}$ (20 mg; Lots \#S0081, \#S0099; Novartis) were kindly provided by the Instituto Vital Brazil/Hygeia Biotechnology LTDA Consortium. Type I water was obtained just before use by deionizing distilled water to less than $1.0 \mu \mathrm{S}$ followed by filtration through a $0.22 \mu \mathrm{m}$-pore membrane. All other reagents were of analytical grade. All buffers and solutions were prepared immediately prior use.

\section{In vitro release profile of octreotide acetate from microparticles}

The particles were dispersed in $2.5 \mathrm{~mL}$ of the diluent according to instructions in the leaflet, added of $17.5 \mathrm{~mL} \mathrm{PBS}\left(8.1 \mathrm{mM} \mathrm{Na}_{2} \mathrm{HPO}_{4}\right.$, $1.8 \mathrm{mM} \mathrm{KH}_{2} \mathrm{PO}_{4}, 2.7 \mathrm{mM} \mathrm{KCl}, 137 \mathrm{mM} \mathrm{NaCl}, 0.02 \%$ sodium azide), homogenized, divided among several tubes, and incubated statically at $37{ }^{\circ} \mathrm{C}$ throughout the experiment. At given time intervals, the samples were centrifuged at $20,000 \mathrm{~g}$ for $30 \mathrm{~min}$ at $12{ }^{\circ} \mathrm{C}$ and the supernatant was separated for quantification of the released octreotide by fluorescence and absorbance spectroscopy as described below. Octreotide acetate (active pharmaceutical ingredient, API) freshly prepared in water and quantified by absorbance measurements at $280 \mathrm{~nm}$ was used as a reference standard for the calibration curves. ${ }^{18}$

The calibration curves of octreotide acetate were prepared in PBS buffer $\left(8.1 \mathrm{mM} \mathrm{Na}_{2} \mathrm{HPO}_{4}, 1.8 \mathrm{mM} \mathrm{KH} \mathrm{PO}_{4}, 2.7 \mathrm{mM} \mathrm{KCl}, 137 \mathrm{mM}\right.$ $\mathrm{NaCl}, 0.02 \%$ sodium azide), in the presence or absence of $0.15 \%$ 
$(w / v)$ PLGA microparticles, followed by the respective quantification protocol (either fluorescamine or Bradford). The standard curves were consequently obtained by plotting the resulting fluorescence intensity at $475 \mathrm{~nm}$ (for fluorescamine assay) or the absorbance at $600 \mathrm{~nm}$ (for the Bradford assay) as a function of the octreotide acetate concentration after proper blank correction. Both precision and linearity were obtained, respectively, from the coefficient of variation $(\mathrm{CV}, \%)$ and the linear regression of the calibration curves. There were no significant differences between calibration curves in fluorescamine assays obtained in the presence or absence of PLGA microparticles. Calibration curves were performed in triplicate. Data were expressed as the percentage cumulative release.

\section{Quantitative analysis of octreotide acetate by} spectrofluorimetry

Quantitative analysis of octreotide acetate was performed by a fluorescence method based on the derivatization of the primary amines of peptides with fluorescamine, resulting in a fluorescent adduct. ${ }^{14,15}$ Aliquots obtained from the in vitro release study were added of equal volume of a fluorescamine solution freshly prepared $(0.5 \mathrm{mg} / \mathrm{mL}$ in DMSO), and the fluorescence was immediately measured in a Jasco FP6300 spectrofluorimeter (Jasco Inc, USA), in a Varian Cary Eclipse (Varian Inc, USA) or in a Spectramax M5 (Molecular Devices, USA) by setting the excitation to $390 \mathrm{~nm}$ and emission to $475 \mathrm{~nm}$.

\section{Quantitative analysis of octreotide acetate by the Bradford assay}

Quantitative analysis of octreotide acetate was performed by a dye-binding assay resulting in the increase in absorbance at approximately $600 \mathrm{~nm} \cdot{ }^{19-21}$ The supernatant obtained from the in vitro release study was added of an equal volume of the Bradford reagent freshly prepared ( 2 x Bradford:20 mg Coomassie G250, $10 \mathrm{~mL}$ ethanol $95 \%, 20 \mathrm{~mL} \mathrm{H}_{3} \mathrm{PO}_{4}$, water up to $100 \mathrm{~mL}$ ) and the absorbance was immediately measured at $600 \mathrm{~nm}$.

\section{Scanning electron microscopy}

Morphological analysis of the particles was performed using scanning electron microscopy (SEM) with two techniques: a) in the dry powder dispersed onto a glass slide and b) after resuspending the powder with the accompanying diluent, dispersion onto a glass slide, plunge frozen in liquid nitrogen and further freeze-drying. Both samples were further coated with $10 \mathrm{~nm}$ gold layer at room temperature and observed in a Quanta ${ }^{\mathrm{TM}}$ Scanning Electron Microscope operating at $25.0 \mathrm{kV}$.

\section{RESULTS}

\section{Microparticles characterization (morphology)}

We have first evaluated the octreotide acetate depot formulation by scanning electron microscopy (SEM). It is well known that polymeric particles can provide varying release profiles depending on several parameters including particle morphology. ${ }^{22}$ We have thus performed of the SEM of the product in order to correlate the experimentally measured kinetic release profile with the particle characteristic. The images obtained by SEM revealed spherical particles with monodisperse size of approximately $30 \mu \mathrm{m}$ (Figure 1). The SEM of the microparticles direct from powder shows an amorphous solid dispersed throughout the sample, as well as retained in the surface of the particles (Figures 1A-1C). The SEM of the microparticles resulting from the hydrated and further freeze-dried formulation shows a uniform, smooth surface (Figures 1D-1F), with no evidences of spongy-like structures, fractures or any probable leaking point. From these results it is likely that the mannitol used in the powder formulation is both freely dispersed in the product as well as adsorbed in the particle surface, which is likely to facilitate the humectation with the diluent. Moreover, it is unlikely to occurs a significant burst phase preceding the typical erosion followed by a progressive drug release.
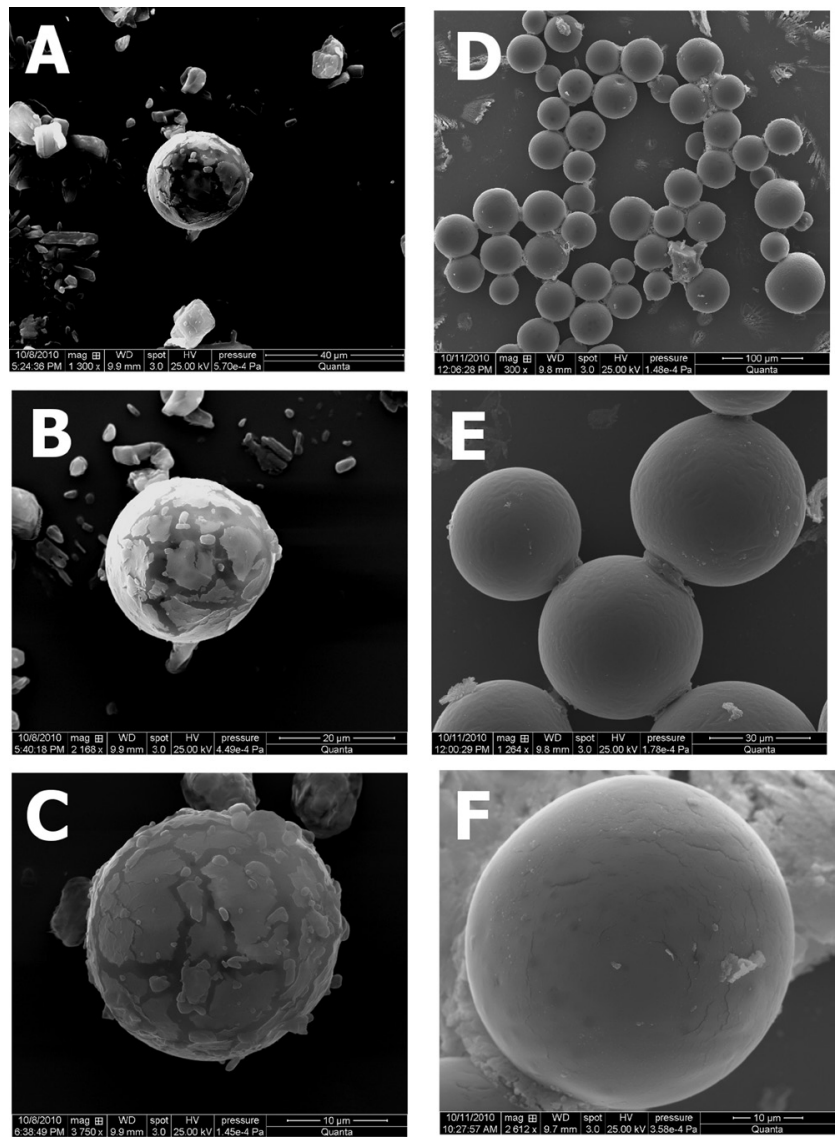

Figure 1. Microparticles characterization by scanning electron microscopy (SEM). Scanning electron microscopy (SEM) was performed with octreotide acetate depot formulation direct from the commercial powder (A to C) or after dispersing the product with its original diluent and further liophylization $(D$ to F). High magnification showing the presence of adhered material on the particle surface $(D)$ and the smooth surface of the particles after resuspending and drying $(F)$. Bar scale states for $40(A), 20(B), 10(C), 100(D), 30$ (E) and $10 \mu \mathrm{m}(\mathrm{F})$

\section{Validation of the spectrofluorimetric method for quantitative} analysis of octreotide

The derivative spectrofluorimetric method for the quantitative analysis of octreotide was validated according to the International Conference of Harmonization (ICH) ${ }^{16}$ and the Brazil's National Health Surveillance Agency (ANVISA) Guidelines. ${ }^{17}$

Linearity was evaluated from three standard curves constructed using twelve concentration levels varying between 0.1 and $100.0 \mu \mathrm{g} / \mathrm{mL}$. The linear correlation coefficient (r) was calculated by adjusting a first order linear regression to data by the least squares method. Data analysis showed linearity $(r=0.990)$ in the concentration range between 5 and $50 \mu \mathrm{g} / \mathrm{mL}$ (Figure 2). 
Table 1. Determination of octreotide by the derivatization-spectrofluorimetric method: intermediate precision and repeatability

\begin{tabular}{|c|c|c|c|c|c|c|c|c|c|}
\hline \multirow{3}{*}{$\begin{array}{c}\text { Concentration } \\
\mu \mathrm{g} / \mathrm{mL}\end{array}$} & \multicolumn{6}{|c|}{ Day 1} & \multirow{2}{*}{\multicolumn{3}{|c|}{$\frac{\text { Day } 2}{\text { Equipment \#2 }}$}} \\
\hline & \multicolumn{3}{|c|}{ Equipment \#1 } & \multicolumn{3}{|c|}{ Equipment \#2 } & & & \\
\hline & Mean & SD & RSD, $\%$ & Mean & SD & RSD, $\%$ & Mean & SD & RSD, \% \\
\hline 5.0 & 4.5 & 0.0 & 0.7 & 3.8 & 0.1 & 3.9 & 4.4 & 0.2 & 5.3 \\
\hline 7.0 & 7.5 & 0.0 & 0.6 & 7.2 & 0.2 & 2.7 & 6.9 & 0.1 & 1.9 \\
\hline 10.0 & 9.1 & 0.2 & 1.8 & 9.7 & 0.3 & 2.9 & 13.2 & 0.3 & 1.9 \\
\hline 20.0 & 20.0 & 0.4 & 2.2 & 22.1 & 0.5 & 2.4 & 21.4 & 0.5 & 2.4 \\
\hline 50.0 & 50.1 & 0.8 & 1.6 & 49.3 & 0.6 & 1.1 & 49.0 & 1.1 & 2.2 \\
\hline
\end{tabular}

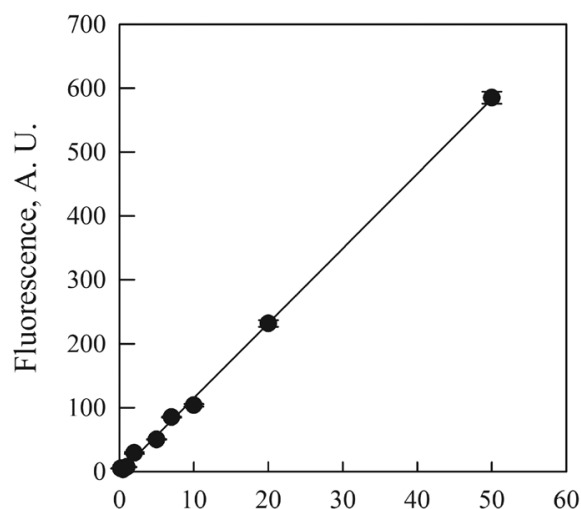

Octreotide Acetate, $\mu \mathrm{g} / \mathrm{mL}$

Figure 2. Calibration curve for the quantitative analysis of octreotide by fluorescamine derivatization. Octreotide acetate diluted with PBS was added of fluorescamine solution and followed by fluorescence measurements

The detection (DL) and quantification (QL) limits were determined from the standard curves as reported elsewhere, ${ }^{16,17}$ from sample at concentrations varying between 5 and $50 \mu \mathrm{g} / \mathrm{mL}$. The detection and quantification limits were calculated as 0.583 and $1.94 \mu \mathrm{g} / \mathrm{mL}$, respectively.

The precision of the method was investigated by testing three concentration levels in triplicate, as follow: low $(5.0 \mu \mathrm{g} / \mathrm{mL})$, intermediate $(20 \mu \mathrm{g} / \mathrm{mL})$ and high $(50 \mu \mathrm{g} / \mathrm{mL})$. The repeatability was evaluated by performing the analysis at the same day and under the same conditions of analysis. The intermediate precision was evaluated by measurements performed at different days using different spectrometers. We have found the repeatability of the method by which RMSD values remained between 0.7 and $3.9 \%$. The intermediate precision is shown by the agreement of the values obtained using different spectrometers (Table 1).

The specificity and selectivity of the method were evaluated by comparing the fluorescence spectra obtained from the following conditions: $20 \mu \mathrm{g} / \mathrm{mL}$ of octreotide in PBS pH 7.4;20 $\mu \mathrm{g} / \mathrm{mL}$ of octreotide in PBS pH 7.4 after centrifugation; $20 \mu \mathrm{g} / \mathrm{mL}$ of octreotide and 5.0 $\mathrm{mg} / \mathrm{mL}$ of depot formulation microparticles in PBS pH 7.4 and 20 $\mu \mathrm{g} / \mathrm{mL}$ of octreotide and $5.0 \mathrm{mg} / \mathrm{mL}$ of microparticles in PBS pH 7.4 after centrifugation. We have observed good agreement between the values, with RSD values lower than $2 \%$ (Table 2 ).

The accuracy of the method was evaluated in triplicate, by adding the reference depot formulation $(5.0 \mathrm{mg} / \mathrm{mL})$ to standard octreotide acetate at three concentration levels $(5,20$ and $50 \mu \mathrm{g} / \mathrm{mL})$. The suspensions were centrifuged $\left(20.000 \mathrm{~g} / 30 \mathrm{~min} / 12^{\circ} \mathrm{C}\right)$ and the supernatants were analyzed by spectrofluorimetry as described above. The accuracy was expressed as the ratio between the averages experimental concentration and the theoretical concentrations. The RSD was 0.2 , 1.4 and $1.0 \%$ for the 5, 20 and 50\% concentration levels, respectively
Table 2. Assessment of specificity and selectivity for the spectrofluorimetric analysis of octreotide in depot formulation

\begin{tabular}{lccc}
\hline & Recovery, \% & SD & RSD, \% \\
\hline a) Octreotide in PBS & 100.0 & 1.6 & 1.6 \\
b) Octreotide in PBS after centrifugation & 100.4 & 1.9 & 1.9 \\
$\begin{array}{l}\text { c) Octreotide and Sandostatin particles } \\
\text { in PBS }\end{array}$ & 96.1 & 0.6 & 0.6 \\
$\begin{array}{l}\text { d) Octreotide and Sandostatin particles } \\
\text { in PBS after centrifugation }\end{array}$ & 103.1 & 1.4 & 1.4 \\
\hline
\end{tabular}

Octreotide acetate $(20 \mu \mathrm{g} / \mathrm{mL})$ was analysed in the absence or in the presence of the depot formulation $(5.0 \mathrm{mg} / \mathrm{mL})$.

(Table 3). The observed recovery values indicate the accuracy of the present method within the linearity range.

Table 3. Assessment of accuracy by recovery of standard octreotide added to reference depot formulation

\begin{tabular}{cccc}
\hline $\begin{array}{c}\text { Concentration, } \\
\mu \mathrm{g} / \mathrm{mL}\end{array}$ & Recovery, $\%$ & SD & RSD, \% \\
\hline 5.0 & 100.2 & 0.2 & 0.2 \\
20.0 & 103.1 & 1.4 & 1.4 \\
50.0 & 99.2 & 1.0 & 1.0 \\
\hline
\end{tabular}

Octreotide acetate at three concentration levels $(5.0,20$ and $50 \mu \mathrm{g} / \mathrm{mL})$ was incubated with the depot formulation $(5.0 \mathrm{mg} / \mathrm{mL})$, the particles were removed by centrifugation and the supernatant subjected to analysis by the spectrofluorimetric method. Experiment was performed in triplicate.

\section{Quantification of the kinetic release of octreotide}

In order to evaluate the octreotide released from the microparticles in the kinetic assay, we resuspended the formulation with the accompanying diluent and PBS, followed by distribution into aliquots and static incubation at $37{ }^{\circ} \mathrm{C}$. We have further conducted a quantitative analysis of the free octreotide by derivatization with fluorescamine and measured the fluorescence of the resulting product (Figures 3A and $3 \mathrm{~B}$ ). The kinetics of release was biphasic with the first phase occurring in the first 10 days, and a second, slower release phase up to 30 days, in agreement with the expected behavior as stated in the product leaflet and HPLC analysis. ${ }^{7}$ In fact, the sensitivity of the present fluorescamine method can be well appreciated in the Figure $3 \mathrm{~B}$, as depicted by the detection of the small transitions from the first phase. In order to inter-validate this method and rule out secondary interference from the formulation components, we used a different method based on the non-covalent interaction of coomassie blue with proteins. ${ }^{19-21}$ Despite of its lower sensitivity, the kinetic release using the Bradford assay resulted in similar behavior using the fluorescamine method (Figures 3C and 3D). 

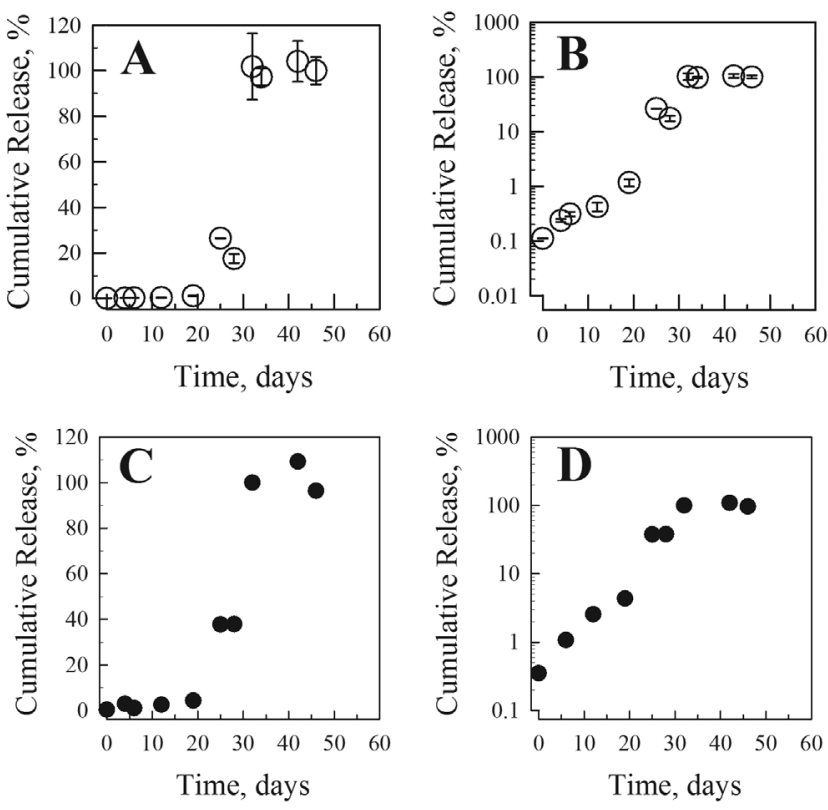

Figure 3. In vitro release of octreotide from microparticles. Octreotide release from microparticles was evaluated by sampling the supernatant at specified time intervals and quantifying the octreotide accordingly. Release was performed at $37^{\circ} \mathrm{C}$ in PBS. Quantification was performed by two unrelated spectroscopic methods: $A$ and B) fluorescence after derivatization with fluorescamine; $C$ and $D$ ) the Bradford method. $B$ and $D$, log scale, depicting the biphasic behavior, with the release in the first phase comprising the 10 first days. Symbols and bars represent, respectively, the mean \pm standard deviation of three independent determinations

\section{DISCUSSION}

We have shown the use of protein derivatizaton with fluorescamine for the continuous measurement of the dissolution profile of octreotide from a commercial depot formulation. To date there is a lack for official compendial methods in pharmacopeias for depot formulations based on peptide and protein products. The present method reported in this work proved convenient since it is a fast, inexpensive, ecologically-friendly (due to the use of only small amounts of organic solvents and reagents) and highly sensitive. According to the present method, it is possible to quantify octreotide spanning a large concentration range. The method reported here proved precise, accurate and linear in the concentration range of 5 to $50 \mu \mathrm{g} / \mathrm{mL}$, which is satisfactory according to current analytical guidelines. ${ }^{16,17}$

We have also shown the high selectivity of our method by the similarity between the kinetic release profile obtained with the use of the fluorescamine and the Bradford assay, as also previously reported by our group for the protein amylin (unpublished results). Moreover, our results are in good agreement with the original kinetic release pattern obtained in the development of the present octreotide acetate depot formulation using RP-HPLC in the quantitative analysis. ${ }^{7}$ This feature indicates that derivatization can be performed directly in the sample without the need of previous removal of the particle that has not been eroded. Additionally, as seen in the microscopic analysis, both dry and reconstituted particles show a smooth surface with no pores of ruptures/fractures, compatible with the slow release observed. The tight correlation between the morphological analysis of the particle and the kinetic release profile observed with the present method provides additional cross-validation between two unrelated methods.

Another great advantage of this method relies in the fact that the remaining non-reacted fluorescamine is decomposed within a few seconds after reaction with water, resulting in only minor fluorescence background which can be conveniently subtracted after blank measurements. This feature eliminates the need for separation of the probe that has not reacted with the released peptide. These characteristics suggests that a kinetic release assay can be conducted by uniform distribution of the product into several fractions in a multiwell plate, covered with a protective seal and, at defined intervals of time, a given number of samples are added to the reactant and immediately read in microplate readers using a reference standard for the quantitative calculation. This approach bring the advantage that any residual particles in the supernatant does not interfere in the analysis, as observed in control measurements showing the lack of reactivity and interference from particles in calibration curve. In opposition, for HPLC analysis a complete removal of particles is needed in order to avoid both damage to equipment and columns.

Collectively, the attributes of the present method indicates the potential of its use in the development of new drug products, increasing the productivity by revising the limiting analytical step by chromatographic analysis, as well as in the development of compendial methods in pharmacopeias for dissolution profile of protein and peptide-based depot formulation.

\section{CONCLUSIONS}

We have developed a method for the fast, sensitive, reliable and convenient analysis of the kinetic release of peptides/protein from polymeric nano/microparticles used for the sustained and controlled release of drug products. This method overcomes the need for full separation of non-eroded particles and uncoupled reactants, also presenting the possibility for the use in high-throughput analysis in multiwell plates. We are confident that the advantages brought by the present method offer the opportunity for the increase in productivity and reduction in analytical cost and environmental impact, limiting steps in the development and analysis of pharmaceutical products.

\section{ACKNOWLEDGMENTS}

We thanks the Instituto Vital Brazil and the Hygeia Biotechnology for the kind donation of Sandostatin ${ }^{\circledR} \mathrm{LAR}^{\circledR}$ and the Octreotide Acetate API. This research was supported by Coordenação de Aperfeiçoamento de Pessoal de Nível Superior (CAPES), Conselho Nacional de Desenvolvimento Científico e Tecnológico (CNPq), Fundação de Amparo à Pesquisa do Estado do Rio de Janeiro Carlos Chagas Filho (FAPERJ) and PRONEX. Funding agencies had no role in study design, data collection and analysis, decision to publish, or preparation of the manuscript.

\section{REFERENCES}

1. Mundargi, R. C.; Babu, V. R.; Rangaswamy, V.; Patel, P.; Aminabhavi, T. M.; J. Controlled Release 2008, 125, 193.

2. Mundargi, R. C.; Srirangarajan, S.; Agnihotri, S. A.; Patil, S. A.; Ravindra, S.; Setty, S. B.; Aminabhavi, T. M.; J. Controlled Release 2007, $119,59$.

3. Li, M.; Rouaud, O.; Poncelet, D.; Int. J. Pharm. 2008, 363, 26.

4. Lancranjan, I.; Bruns, C.; Grass, P.; Jaquet, P.; Jervell, J.; Kendalltaylor, P.; Lamberts, S. W. J.; Marbach, P.; Orskov, H.; Pagani, G.; Sheppard, M.; Simionescu, L.; Metab., Clin. Exp. 1995, 44, 18.

5. Davaran, S.; Omidi, Y.; Rashidi, M. R.; Anzabi, M.; J. Bioactive Comp. Pol. 2008, 23, 115.

6. Comets, E.; Mentre, F.; Nimmerfall, F.; Kawai, R.; Mueller, I.; Marbach, P.; Vonderscher, J.; J. Controlled Release 1999, 59, 197. 
7. Bodmer, D.; Kissel, T.; Traechslin, E.; J. Controlled Release 1992, 21, 129.

8. Murty, S. B.; Wei, Q.; Thanoo, B. C.; Deluca, P. P.; AAPS PharmSciTech 2004, 5, 49.

9. Wang, J.; Wang, B. M.; Schwendeman, S. P.; Biomaterials 2004, 25 , 1919.

10. Wang, J.; Wang, B. A.; Schwendeman, S. P.; J. Controlled Release 2002, 82, 289.

11. Petersen, H.; Bizec, J. C.; Schuetz, H.; Delporte, M. L.; BMC. Res. Notes 2011, 4, 344.

12. Rhee, Y. S.; Sohn, M.; Woo, B. H.; Thanoo, B. C.; Deluca, P. P.; Mansour, H. M.; AAPS PharmSciTech 2011, doi: 10.1208/s12249-0119693-z.

13. Ghassemi, A. H.; van Steenbergen, M. J.; Barendregt, A.; Talsma, H.; Kok, R. J.; van Nostrum, C. F.; Crommelin, D. J.; Hennink, W. E.; Pharm. Res. 2012, 29, 110.

14. Udenfriend, S.; Stein, S.; Bohlen, P.; Dairman, W.; Leimgruber, W.; Weigele, M.; Science (Washington, DC, U. S.) 1972, 178, 871.
15. De, B. S.; Weigele, M.; Toome, V.; Manhart, K.; Leimgruber, W.; Bohlen, P.; Stein, S.; Udenfriend, S.; Arch. Biochem. Biophys. 1974, 163, 390.

16. ICH - International Conference on Harmonization; Q2R1-Validation of Analytical Procedure: Text and Methodology, http://www.ich.org/ fileadmin/Public_Web_Site/ICH_Products/Guidelines/Quality/Q2R1/ Step4/Q2_R1_Guideline.pdf, accessed in January 2012.

17. Agência Nacional de Vigilância Sanitária - ANVISA; GRE nº 899 de 29/05/2003: Guia para validação de métodos analíticos e bioanalíticos, Ministério da Saúde: Brasil, 2003.

18. Pace, C. N.; Vajdos, F.; Fee, L.; Grimsley, G.; Gray, T.; Protein Sci. 1995, 4, 2411

19. Bradford, M. M.; Anal. Biochem. 1976, 72, 248.

20. Georgiou, C. D.; Grintzalis, K.; Zervoudakis, G.; Papapostolou, I.; Anal. Bioanal. Chem. 2008, 391, 391.

21. Zor, T.; Selinger, Z.; Anal. Biochem. 1996, 236, 302.

22. Fredenberg, S.; Wahlgren, M.; Reslow, M.; Axelsson, A.; Int. J. Pharm. 2011, 415,34 . 